\title{
Research on Construction Models of Adult Learning Circle in China
}

\author{
Hefei Li \\ North China University of Science and Technology, Tangshan, 063000, China
}

Keywords: Adult learning circle, Construction models, Autonomous learning

\begin{abstract}
Soon after the adult learning came out in Sweden, the Swedish government regarded adult learning circle as one of the effective measures to improve the scientific and cultural quality of the majority of workers, and achieved good results. The adult learning circle in China is built late and the pattern is immature. This paper refines the basic characteristics of adult learning. Based on the adult learning features, the paper gives the construction strategies of adult learning circle in China to provide some references for the relative researchers.
\end{abstract}

\section{Introduction}

Adult learning circle first appeared in Sweden. It has been more than 100 years of history. As an open and informal collaborative learning technology, adult learning circle has made outstanding contributions to the prosperity and development of Swedish society. It has also been popularized in many countries and regions, and has become an important way of adult learning. Adult educators are more interested in learning skills than adults, and are more interested in learning methods than learning goals. Most of the research on adult learning circle in adult education in China focuses on the experience of Sweden. However, there are few studies on adult learning circle based on philosophical theory. However, the construction and development of adult learning circle in philosophy benefit the development and influence of the research achievements and penetration, needs a systematic and profound theoretical guidance, it is necessary for the analysis of adult learning circle is the philosophical foundation. This paper refers to the philosophical foundation of adult learning circle is related to the content of adult education philosophy, including the philosophy of adult education in the field of social change: the role of adult education meaning, adult needs and interests, adult education contents and methods, theory of adult development and significance, curriculum and curriculum objectives, teaching process and learning process, education. Any kind of adult education philosophy is in a certain society, history and culture as background, has its own particularity, it reveals the basic law of the adult education promoted the development of adult education, which has certain guiding significance for modern adult education activities. Based on the analysis of modern humanism in the philosophy of adult education, this paper reveals the essence of adult learning circle. All learning takes place through two different processes. We may not feel that learning has gone through two different processes, because in most cases they happen at the same time. The construction of adult learning circle in our country must be based on the understanding of the basic characteristics of adult learning.

\section{Basic Characteristics of Adult Learning}

\subsection{Autonomy of Adult Learning}

As the learning course is chosen by adults themselves after investigation, the motivation of learning is full. In the process of learning will give full play to their subjective initiative, active learning, willing to learn, in the learning process is good at finding problems and solving problems, enthusiasm and creativity also fully play out, learning efficiency will naturally get twice the result with half the effort. In addition, because adult learning goals are very clear, they often think a lot of problems, with problems to learn, will listen more seriously. Self-concept is from the characteristics 
of adult personality depends to the independent personality, therefore, adult learning usually has the characteristics of self-directed learning. Whether or not they help others, actively diagnose their learning needs, establish learning goals, identify the human and material resources needed for learning, choose and practice appropriate learning strategies, and evaluate the learning outcomes of this process is self-directed learning. Adults about their life goals and habits of the understanding, what to learn, how to learn, what to learn have their own ideas, love in the middle school, in an informal learning environment is the most effective, love of learning with different learning methods, rote learning they will repel. We enrich the form and means of training in accordance with local conditions, and use the Internet platform to build a blended learning system based on online and offline, encourage employees to learn in spare time, flexibly design training content, so that staff learning is not limited to the training of the company's organization. Compared to minors, adults how to control their own learning process have a stronger sense of self, which includes the initiative to develop appropriate learning goals, and actively integrate resources, steps to carry out the learning and learning effect, self-assessment and guidance, correct their learning behavior, learning task.

\subsection{Practicability of Adult Learning}

Adult learning will often be closely related to his social role and development task. Adult learning is driven by the actual needs of adult learners, and inevitably encounter various problems in the process of social practice. Adult learning is usually problem centered rather than subject centered. Problem is the natural unit of adult learning. In this process, adults not only improve their level of reflection and theoretical level, but also improve their practical ability and ability to solve problems. Adult learning needs are often related to their own social roles and tasks, and it has a strong reality. Adults have a certain amount of work experience and experience, and they will judge themselves based on experience. If the training can bring new knowledge and its experience with the combination of practical work and, to awaken and sublimate their experience, training content can fall to the actual work, that is used to study, improve their work and life, can make them feel learned something. That training is to enhance students' attitude, knowledge and skills, but in fact, a person's attitude depends on many factors, only rely on a training cannot be changed, but also the accumulation of knowledge of life, a training is difficult to significantly increase the most, is some perception. In addition to general training, enterprise training should focus on skills training, and must be the kind of practical dry courses. This requires the training organizers to develop a pair of insight, know the enterprise staff skills short board, targeted, to the use of learning, the use of experienced and practical internal and external lecturers teaching, forms can also be varied.

\subsection{Utility of Adult Learning}

Unlike compulsory education or university education, adult learning required courses are the school uniform arrangements, individuals do not have the right to choose. Adult learning is different. They can choose learning courses according to their interests, career prospects and the value of creativity. When adults choose to learn a course, they will ask the relatives and friends or the people who have contacted the course, and compare their economic, feasibility and usefulness. Investigate the qualification, teaching force and charging standard of the training class. Adults will consider repeatedly, repeatedly contrast, repeated surveys, and ultimately determine the learning courses and training courses. Adult learning purpose is very clear, preparation is also very sufficient. The competition between the society and the workplace is fierce, and the staff participate in the training is to improve their own value through training and learning, to achieve the job, job promotion or get better career development, shorten the gap between reality and the ideal purpose. This is also the reason why academic qualifications and professional qualifications are studied in droves. As more and more high-quality labor force, the age of the Internet and means of learning resources is very rich, they will be based on environmental analysis, according to their actual selective learning, for they cannot meet the needs of the training courses or not enough to improve their skills training content, they will choose to deal with and escape. In this regard, as the person in charge of training should understand the business, understand the training needs of real employees, according to the actual 
situation of the ability of employees, and business departments to develop training programs, rather than head, training courses to follow the fashion concept or how many years do not update the. Of course, a good training and learning atmosphere also depends on whether employees have the pursuit. The purpose of adult learning comes from practice the knowledge that will be used now will be carefully mastered by them. At present, they can break up a complete learning system into countless fragments and selectively learn.

\section{Construction Models of Adult Learning Circle}

\subsection{Tolerant Learning Environment}

Each adult learner has his own unique cognitive style, knowledge or skill level. Adult teachers should understand that when students understand things differently or make mistakes, don't be afraid and feel inferior, because teachers can understand and understand them. Through dialogue and communication, adult teachers can understand where students have problems and why problems occur, so that the problems can be corrected in time. In addition, adult learners in the knowledge and experience of adult teachers through each one has his good points, forms of assessment, understand the differences between students, using special teaching assignments, peer tutoring, cooperative learning or differences, give full play to the initiative of students, make each student fully understand and master the knowledge. To overcome the obstacle of learning defense, it is necessary to create a safe and inclusive learning environment, to maintain adult learners' self-value, identity and dignity affirmation. For adult learners, it is necessary not only for success, is the need for the liberation of individuality. Adult learners are influenced by the growth environment and are biased against some people and things when they are referred to as adults. They cannot be blamed for learning these knowledges intentionally or unintentionally, because understanding and forgetting prejudice is a lifelong process. To create a safe and respectful learning environment, adult learners should be encouraged to eliminate prejudices, respect and share knowledge. When adult learners feel that they have and share their thoughts as the respected behaviors in the learning environment, they may be more willing and bold to express their ideas. In fact, this is also the main way for them to produce knowledge, that is, to have a variety of viewpoints on any issue, and to know how to construct their own knowledge and grasp the truth.

\subsection{Cooperative Learning Strategy}

Adult learning activities although self-centered, but their self-development and growth are not isolated, the comprehensive development of an isolated individual learning activities is not conducive to adults and improve learning efficiency, encourage each other and collaborative environment more conducive to adult learning. Modern also pays attention to people's collaborative learning. The purpose of these groups of learning is to promote adult choice, creation, evaluation and self-actualization in collaborative learning. The learning style of adult learning circle is like group learning, but it is more flexible and diverse than ordinary group learning, and the goal is more long-term. In adult learning circle, adult students from different fields and positions are gathered together, they have different educational backgrounds and personal specialties, and their collaborative learning has also realized the sharing of rich adult learning resources. Under the collision of different ideas and views, students get inspiration in the learning circle, to give full play to their own creativity. The learning in adult learning circle is different from the traditional adult education activity. There are no teachers and students in the identity of the participants. The organizers, learning materials and participants constitute the iron triangle of the learning circle. The organizers of the study circle are responsible for providing students with venues and learning materials, rather than the leader of learning activities, without the usual authority in teaching. He and other students communicate and learn based on equal status. Modern philosophy believes that the ideal of the learning circle organizers should pay attention to respect every adult students, but also pay attention to the use of the learner's experience and potential, promoting adult learning activities in 
the new knowledge and original experience combined with their own actual work and life together, realize the knowledge structure and optimize the working and living conditions to improve. This requires that the organizers of adult learning circle should first have a comprehensive understanding of students participating in learning, and pay attention to the usual communication and communication with students.

\subsection{Diversified Curriculum Design}

Curriculum refers to the learning process and route of the learner, which includes not only the knowledge of various disciplines, but also the methods of learning. The modern humanism thought to cultivate self-realization, set up the students' various needs of the curriculum is very important in the process of education, such as literature, philosophy, history, social, political and other aspects of the curriculum in the investigation carried out at the same time, also cannot ignore the adult self-value, idea and feeling. There are many kinds of learning courses in adult learning circle, but this diversity is not based on the personal interests of an organizer or the interests of an organization, but should be based on the full participation of adult students in decision-making. At the same time, the government's relevant education departments should also provide sufficient funds and policy support in the premise of respecting the autonomy of adult learning circle. Only in this way can the curriculum be in line with the adult's personal interest and development plan, and provide enough space for adults. Therefore, in the course selection and organization process, we should emphasize the synergy of all adult students, and ask for consultation and Discussion based on mutual respect. The key to learning resistance is not to overcome it, but to make the best of its potential. Study of impedance including construction potential, knowledge construction is a kind of motivation, if combined with life potential, can also choose to develop, and finally the formation of very large learning motive force to go beyond learning, so the impedance can cause learning and development of new. However, the impedance of failure is usually transformed into defense, which can interfere with learning. In the adult learning circle, the interpersonal relationship is also very important, each person in the pursuit of autonomy and self-realization, but also respect the rights of others.

\section{Conclusion}

The diversity of curriculum design is to study and guide the practice of adult learning circle with the basic characteristics of adult learning. It is more conducive to grasp the nature of learning activities, mobilize the enthusiasm of adult learners, and get more support. However, the basic characteristics of adult learning emphasize more on the psychological needs and development of human beings, and lack of in-depth study on the guiding ideology of practical activities such as curriculum design and implementation. In the research and practice of adult learning circle, we should also absorb other ideas to promote the further development of adult learning circle in China.

\section{Acknowledgement}

This paper is the result of the Social Science Fund Project of Hebei Province named "Research on the Establishment of Adult Learning Circle in Our Country Based on Comparison between China and Korea” (Grant No. HB16JY061).

\section{References}

[1] Li Chun. Adult Learning Barriers - Based on a Comprehensive Learning Theory [J]. Journal of Continuing Higher Education, 2016, 29(1): 44-48.

[2] Ouyang Zhongming, Ren Xin, Tian Lijun. Research on the Adult Learning Policies in South Korea under the Framework of Lifelong Learning [J]. Vocational and Technical Education, 2016, 37(7): 69-74.

[3] Huang Riqing, Huang Xuanwen. The Creation and Development of Adult Learning Circle in 
Sweden [J]. Adult Education, 2008(1): 91-94.

[4] Qi Youju, Jiang Rongrong. Swedish Adult Vocational Education and Its Enlightenment to China Open Education Practice [J]. Journal of Distance Education, 2016(5): 69-75. 